\title{
EXTRATO DO RELATóRIO DO SECRETÁRIO DA FACULDADE DE DIREITO, REFERENTE A 1950
}

\author{
DIRETORIA E CONSELHO TECNICO
}

Exerceu a Diretoria da Faculdade de Direito, durante o ano de 1950, o Professor Braz de Sousa Arruda, nomeado por decreto do Sr. Governador do Estado, de 21 de junho de 1949. A Vice-Diretoria da Faculdade foi exercida pelo Professor Lino de Morais Leme, nomeado para êsse cargo por decreto do Sr. Governador do Estado, de 27 de outubro de 1949, tendo tomado posse no dia 8 de novembro do mesmo ano.

O Conselho Técnico-Administrativo esteve assim constituido: Professores Braz de Sousa Arruda, Antonio de Sampaio Dória, Waldemar Ferreira, Noé Azevedo, Alvino Ferreira Lima e Basileu Garcia.

Em junho, o Conselho Técnico-Administrativo foi renovado, passando a ser constituido dos seguintes membros: Professores Braz de Sousa Arruda, Antonio de Sampaio Dória, Alvino Ferreira Lima, Basileu Gancia, Gabriel de Rezende Filho, Ernesto Leme e Miguel Reale.

\section{CONGREGAÇ.̃̃O}

Foram objeto de deliberação da Congregação, entre outros, os assuntos abaixo discriminados.

Em 5 de janeiro a Congregação resolveu designar os Professores Jorge Americano, J. C. Mendes de Almeida, Siqueira Ferreira e Th. Monteiro de Barros Filho para elaborarem o regimento de que trata o art. 2.0 da Lei n. 662, do mesmo mês, sôbre o funcionamento dos cursos noturnos; e, na sessão do dia 12 foi discutido, emendado e aprovado o referido projéto.

Na sessão de 12 de janeiro, pelo Professor José Soares de Mello foi dito que desejava propor que a Congregação estudasse a questão das aulas práticas, não permitindo que pessoas estrandas dessem aulas na Faculdade. A Congregação aprovou essa proposta, ten- 
do o Sr. Diretor comissionando os Professores Vicente Ráo, Ernesto Leme e Soares de Mello para o estudo do problema.

Em 16 de fevereiro a Congregação elegeu a comissão de redação da "Revista" da Faculdade de Direito, que ficou composta dos Professores Ernesto Leme, Th. Monteiro de Barros Filho e Almeida Junior.

Na mesma sessão, a comissão constituida pelos Professores Vicente Ráo, Ernesto Leme e Soares de Mello, encarregada de estudar a questão das aulas práticas, apresentou o seu provimento, ao qual se apresentaram emendas aditivas e substitutivas, aprovando-se sua redação final.

O Professor Almeida Junior apresentou a seguinte proposta: "Proponho que seja constituida uma comissão para o fim de estudar a conveniência e a possibilidade de organizar-se uma biblioteca circulante, com as duplicatas já existentes na Biblioteca e mais as que forem adquiridas por esta. Destinar-se-á essa biblioteca ao uso exclusivo dos alunos da Faculdade. Sala da Congregação, 16 de fevereiro de 1950. as.) Almeida Junior" O Sr. Diretor dá diversas explicações sôbre as medidas que tomou relativamente à biblioteca, que qualifica de "criação" da Faculdade, sendo aceita a proposta do Professor Almeida Junior e designados os Professores Noé Azevedo, Siqueira Ferreira e Almeida Junior, para comporem a aludida comissão.

Em 4 de março, a Congregação, de acôrdo com o art. 57 da Lei r.o 3023 de 15-7-37, tomou conhecimento das inscrições para o concurso de professor catedrático de Direito Constitucional, cujo prazo se encerrara no dia 3. Concorreram à inścrição os Drs. José Pinto Antunes, Candido Motta Filho, Percival de Oliveira e o Bel. Odilon de Araujo Grellet. Foram aceitas as inscrições, por ter a Congregação verificado que estavam formalmente preenchidas as condições do art. 57 da lei n.o 3023. A Congregação passou a decidir, em seguida, por proposta dos Professores Waldemar Ferreira e Soares de Mello, se se elegeriam ou não os professores da Faculdade, que deveriam fazer parte da Comissão Examinadora do referido concurso. Resolvendo a Congregação proceder à eleição, elegeram-se examinadores os Professores Ernesto Leme e Th. Monteiro de Barros Filho e suplentes os Professores Mário Masagão e Waldemar Ferreira.

Na mesma sessão o Prof ess or Waldemar Ferreira, apresentou a seguinte proposta relativa ao prêmio Carvalho de Mendonça: "Considerando que o aluno Roberto Machado Moreira se distinguiu no curso de Direito Comercial no triênio 1946-1948, obtendo nos exames finais da disciplina a média 10; considerando que, nessas condições, merece êle o Prêmio Carvalho 
de Mendonça; - os diretores da Fundação Prêmio Carvalho de Mendonça propõem que a Congregação dos Professores da Faculdade de Direito: a) conceda ao estudante Roberto Machado Moreira o prêmio correspondente ao triênio 1946-1948; a) que o prêmio lhe seja entregue na sessão solene de abertura dos cursos dêste ano. O prêmio consistirá em diploma a ser expedido pelo Exmo. Sr. Liretor da Faculdade de Direito, e na oferta de coleção do Tratado de Direito Comercial Brasileiro, de autoria do patrono, e de um cheque no valor de $\operatorname{Cr} \$ 1.500 .00$. São Paulo, 4 de março de 1950. ass.) Waldemar Ferreira - Ernesto Leme". A proposta foi aprovada unanimemente.

Em 23 de março, o Sr. Diretor informou sobre a sítuação do Curso de Doutorado tendo sido distribuidos os pareceres que, sôbre o referido curso, foram apresentados pelos Professores Jorge Americano e Siqueira Ferreira e o voto divergente dado pelo Professor Braz Arruda. Abertos os debates, a Congregação resolveu votar, em primeiro lugar, a reabertura, ou não, do Curso de Doutorado. Requerida votação nominal verificou-se que houve maioria de votos a favor da reabertura do Curso. Resolveu ainda a Congregação que o Curso de Doutorado funcionaria como está e que uma comissão de professores, designada pelo Sr. Diretor daria parecer soßre as possiveis modificações do regulamento daquele Curso. Para tal fim, foram designados os Professores: Waldemar Ferreira, Lino Leme e Soares de Mello.

Em 25 de maio, durante o expediente, o professor Siqueira Ferreira, propôs que, tendo o Professor Waldemar Ferreira completado, no corrente mês, vinte e cinco anos de exercício no magistério, se consignasse em ata um voto de congratulações ao referido professor e que a Faculdade publicasse um número especial da "Revista" em homenagem ao aludido professor. As propostas foram aprovadas unanimemente, tendo o Professor Waldemar Ferreira agradecido. Na ordem do dia, a Congregação procedeu à eleição para renovação do Conselho Técnico-Administrativo, no qual terminaram os mandatos os Professores Braz de Sousá Arruda e Waldemar Ferreira. Procedida a eleição em escrutinio secreto verificou-se que os Professores mais votados foram: Mário Masagão, Waldemar Ferreira, Gabriel de Rezende Filho, Ernesto Leme e Siqueira Ferreira. O Professor Mário Masagão agradece a sua eleição, declarando não poder aceitar a indicação, por ser desembargador do Tribunal de Justiça. Assim, foram enviados à Reitoria, para a nomeação, os nomes dos professores já mencionados, exceptuando-se o do Professor Mário Masagão. 
o segundo assunto da ordem do dia tratava da indicação de auxiliares de ensino para o curso noturno, apresentada pelo Professor Lino Leme e pelo livre docente Dr. Gama e Silva. O Sr. Diretor esclareceu que, tendo recebido as indicações, entendera que os auxiliares nomeados o foram para todo o serviço. Entretanto, tendo dúvidas a respeito, resolvera submeter o assunto à Congregação. Abertos os debates, neles intervêm diversos professores, tendo o Professor Soares de Mello, por fim, apresentado a seguinte proposta:

"Considerando que se acha em estudos o novo Regulamento da Faculdade de Direito, no qual serão convenientemente disciplinados os serviços dos auxiliares de ensino; considerando ainda que, nas bases ora vigentes, a instituição dos auxiliares de ensino não deu os resultados que se esperavam:

- resolve a Congregação considerar extinta a função de auxiliar de ensino da Faculdade de Direito, a partir de $10^{\circ}$ de julho dêste ano, rescindidos os respectivos contratos" Submetida a votos, em votação nominal, foi esta proposta aprovada por dez votos contra quatro.

Em seguida, foi lido o parecer do Professor Basileu Garcia, aprovado pelo Cionselho Técnico-Administrativo, relativo ao projeto de lei n. ${ }^{\circ}$ 234, da Assembléia Legislativa, projeto êsse que cria diversos cargos nesta Faculdade. A Congregação, depois, resolveu adiar para a próxima sessão a discussão da proposta de reforma da lei n. 3023 , apresentada por diversos professores. Logo após, o Professor Waldemar Ferreira pediu dispensa da comissão encarregada de elaborar o novo regulamento da Faculdade, tendo sido designado para substituí-lo o Professor Siqueira Ferreira.

Outros assuntos decididos em Congregação foram os seguintes: 1) que o Curso de Doutorado tenha início em março de 1951; que funcione, desde já, um curso livre de introdução ao Curso de Doutorado, considerando-se inscritos os candidatos já selecionados para o Doutorado; 2) aceitar a inscrição dos bachareis Antonio Chaves e Alexandre Augusto de Castro Corrêa, respectivamente para prestarem concursos para as livres docências de Direito Internacional Privado e Direito Romano; 3) eleger o professor Noé Azevedo representante da Congregação junto ao Conselho Universitário, e o Professor Basileu Gancia para suplente: 4) aprovar os pareceres das comissões examinadoras dos 
concursos para a livre docência de Direito Internacional Privado e de Direito Romano, no sentido de ser o candidato à primeira dessa c a ld e i r a considerado inabilitado e habilitado o candidato Alexandre Augusto de Castro Corrêa; 4) patrocinar, juntamente com a Reitoria da Universidade de São Paulo e o Instituto dos Advogados, conferências, realizadas na sala João Mendes, do Professor Jimenez de Asúa, criminologista espanhol, e do Professor Riené David, catedrático de Direito Comparado da Faculdade de Direito de Universidade de Paris; 5) autorizar o Professor Hilário Veiga de Carvalho a realizar um curso de criminologia de acôrdo com programa já aprovado pelo Conselho Técnico-Administrativo, realizando-se as aulas à noite, na Sala João Mendes.

\section{CONSELHO TECANICO-ADMINISTRATIVO}

Dentre as deliberaçỏes do Conselho Técnico=Administrativo, destacamos as seguintes: 1) autorizar o Sr. Diretor a providenciar junto à Reitoria da Universidade a fim de atender às despesas de viagem do Professor Tulio Ascarelli, para realizar na Faculdade um curso de Direito Comparado Latino-Americano; 2) autorizar o livre-docente Dr. Hilário Veiga de Carvalho a realizar um curso de criminologia, de acôrdo com o programa apresentado; 3) aprovar o relatório da revisão procedida nos livros de escrituração, papéis e valores da Tesouraria ida Faculdade, apresentado pelo contador Julio A. Pinheiro de Carvalho; 4) indeferir o requerimento de dispensa da taxa de transferência de um interessado; 5) designar o Professor Basileu Garcia para estudar o processo n. ${ }^{\circ} 4082$ de 1950, da Reitoria, no qual a Assessoria Técnico-Legislativa da Assembléia Legislativa do Estado solicita o pronunciamento dêste Instituto sobre o projeto de lei n.o 234, relativo à reforma do Regulamento da Faculdade de Direito; 6) indicar os nomes dos Professores Albérico Fraga, da Baia, Ruy Cirne Lima, do Rio Grande do Sul e Haroldo Valladão, do Rio de Janeiro, para examinadores do concurso de Direito Constitucional; 7) iniciar, no dia 20 do corrente, as aulas dos Cursos de Bacharelado, aprovados os respectivos horários; 8) iniciar as aulas do Curso de Doutorado no $2.0^{\circ}$ semestre dêste ano; 9) adotar o parecer do Professor Basileu Garcia, referente ao projeto de lei 234, da Assembléia Estadual, parecer que mandou remeter à Congregação; 10) deferir os requerimentos de sete alunos que pertecem ao 
C. P. O. R., deliberando, outrossim, que os alunos impedidos de comparecer a exames, por motivos militares, deverão requerer, na época regulamentar, os exames que perderam; 11) deferir, a partir de 11 de outubro de 1950 , o requerimento de recondução do livre docente Luiz Eulálio de Bueno Vidigal; 12) iniciar as aulas do Curso de Doutorado no dia 1.? setembro; 13) deferir o requerimento de recondução do livre docente Sinésio Rocha; 14) deferir, excepcionalmente, os pedidos de transferência do curso diurno para o noturno, e vice-versa, ficando estabelecido que, desta data em diante, os pedidos idênticos deverão ser feitos sòmente na época das matrículas; 15) deferir o requerimento de recondução do livre docente Dr. José Antonio de Almeída Amazonas.

\section{GURSO DE DOUTORADO}

A Congregação deliberou que funcionasse, de setembro a novembro de 1950, o Curso Livre de Introdução ao Curso de Doutorado, para os alunos já selecionados pela Secretaria da Faculdade, curso êsse com as mesmas cadeiras do Doutorado, e regido pelos seguintes professores: História do Direito Nacional - Professor Waldemar Ferreira; Direito Civil Comparado - Professor Lino de Moraes Leme; Criminologia - Professor José Soares de Mello; Direito Público, Teoria Geral do Estado e Partes Especiais - Professor Miguel Reale.

\section{CURSO DE DIREITO COMPARADO}

Funcionou, em setembro, o Curso de Direito Comparado LatinoAmericano, regido pelo Professor Tullio Ascarelli, especialmente contratado pela Reitoria da Universidade.

\section{BIBLIOTECAA CIRCULANTE}

Em outubro de 1950 foi instalada a Biblioteca Circulante da Faculdade de Direito, a fim de promover o empréstimo de livros a alunos e demais interessados. 


\section{AFASTAMENTOS E LICENÇAS DE PROFESSORES}

Professor J. J. Cardozo de Miello Neto - com exiercf́cio na Câmara Federal de Deputados, até 6 de Julho, quando reassumiu o exercicio de seu cargo. Foi substituido pelo Professor Ernesto Leme.

Professor Spencer Vampré - em gozo de licença em prorrogação, para tratamento de saude. Foi substituido pelo Professor Miguel Reale.

Professor Honório Fernandes Monteiro - com exercício no cargo de Ministro do Trabalho, até quanto pediu exoneração, para continuar na Câmara de Deputados.

Professor J. C. de Ataliba Nogueira - com exercício na Câmara Fiederal de Deputados sendo substituido pelo livre docente Dr. Genésio de Almeida Moura.

Livre docente Dr. Silvio Marcondes Machado - nomeado, por ato de 4 de abril, do M. Reitor, para substituir o Professor Honório Monteiro, a partir de 1 de Abril.

Professor S. Soares de Faria - dispensado, por ato de' 4 de Abril, do M. Reitor, da substituição ao Professor Honório Monteino, a partir de $10^{\circ}$ de Abril.

Professor Alvino Ferreira Lima - obieve, por decreto de 11 de Abril do Sr. Governador do Estado, içncessão de mais a sexta parte de seus vencimentos, a partir de 10 de Julho de 1949.

Professor Miguel Reale - designado, por ato de 14 de Março do Sr. Governador do Eistado, para representar o Govêrno na Comissão da UNESCO.

Livre docente Dr. Luiz Antonio da Gama e Silva - nomeado, por decreto de 30 de Abril, do Sr. Governador, para substituir 0 Professor Sampaio Doria, na regência da cadeira de Dirneito Internacional Privado, do $5^{\circ}$. ano, a partir de $1^{\circ}$. de Abril, em virtude da licença para tratamento de saúde concedida áquele professor.

Professor Ernesto Leme $\longrightarrow$ nomeado, por ato de 7 de Junho, do Magnifico Reitor, para exercer as funções de membro do Conselho Técnico-Administrativo, desta Faculdade.

Professor Gabriel de Rezende Filho - nomeado, por ato de 7 de Junho, do Magnífico Reitor, pora exercer as funções de membro do Conselho Técnico-Administrativo, desta Faculdade.

Professor Miguel Reale — exonerado, a pedido, do cargo de Reitor da Universidade, por ato de 20 de Junho, do Sr. Governador 
Professor Noé Azevedo - afastado, por ato de 21 de Junho do Magnffico Reitor, devidamente autorizado pelo $\mathrm{Sr}$. Governador pelo prazo de três meses, a fim de tomar parte, como repre. sentante desta Faculdade, em conferências e congressos a se realizarem em Londres, Haia e Paris, de acôrdo com o programa pré-estabelecido. $\mathrm{O}$ afastamento verificou-se a partir de 10. de Julho.

Livre docente Dr. Flavio Queiros de Mores - nomeado, por decreto de 18 de Julho, do Sr. Governador, para substituir o Professor Noé Azevedo, a partir de $10^{\circ}$ de Julho, enquanto durar seu impledimento.

Livre docente Dr. Luis Antonio da Gama e Silva - nomeado, por decreto de 18 de Julho, do Sr. Governador, para substituir o Professor Sampaio Doria, licenciado para tratamento de saúde.

Professor Antonio Ferreira 'Cesarino Junior ־ laflastado, durante os meses de Junho e Julho, por ato de 30 de Março do Magnificlo Reitor, devidamente autorizado pelo Sir. Governador, a fim de ausentar-se do país, em viagem do intercâmbio cultural.

Professor S. Soares de Faria - designado, por ato de 28 de Agosto, do Magnífico Reitor, para substituir o Professor Cesarino Junior, enquanto durar seu impedimentio.

Professor Vicente Ráo - designado, por decreto de 31 dé Agosto do Excelentíssimo Senhor Presidente da República, para fazer parte da delegação que representará o Brasil na V.a Sessão da Assembléia Geral das Nações Unidas, a reunir-se em Nova York, em setembro de 1950.

Por ato de 11 de outubro, do Magnifico Reitor, devidamente autorizado pelo Sr. Governador, foil concedido afastamento ao Professor Ráo pelo prazo que for necessário, a partir de $1^{\circ}$. de Setembro, a fim de participar da $\mathrm{V}^{\mathrm{a}}$. Sessão da Assembleia Greral das Nações Unidas, como Delegado do Brasil.

Livre docente Dr. Octavio Moreira Guimarães - nomeado, por decreto de 4 de Outubro, do Sr. Governador, para substituir o Professor Vicente Ráo, a partir de 2 de Setembro.

Livre docente Dr. Paulo de Campos Filho - nomeado, por decreto de 5 die Setembro, do Sr. Governador, para substituir o Professor Jorge Americano, durante o seu impedimento, por motivo de licença para tratamento de saúde, a partir de $10^{\circ}$ de Agosto.

Professor J. C. Mendes de Almeida - designado, por ato de 11 de Outubro do Magnúfico Reitor, para substituir o Professor Mário Masagão, a partir de 23 de Setembro, em virtude de o referido professor haver requerido licença-prêmio. 
Livre docente Luiz Antonio da Gama e Silva - nomeado, por decreto Ide 24 de Outubro, do Sr. Governador, para substituir o Professor Sampaio Dória, licenciado para tratamento de saúde, a partir de 1.0 de Outubro.

Professor Antonio Ferreira de Almaida Junior - afastado, de 12 de Outubro a 11 de Novembro, em virtude de haver sido comissionado pora tomar parte no Congresso de Educação a realizar-se em Montevidéo, Uruguai.

Livre docente Dr. Hilário Veiga de Carvalho - nomeado, por decreto de 31 de Outubro, do Sr. Governador, para substituir o Professor Almeida Junior, durante o seu impedimento.

Professor Alvino Ferreira Lima - designado por ato de 7 de Novembro do Magnifico Reitor, para substituir o Professor Ernesto Leme, a partir de 16 de Agosto, em virtude de haver-lhe sido concedida licença-prêmio de três meses;

Professor Lino de Moraes Leme - designado, por ato de 14 de Novembro do Magnúfico Reitor, para reger a 3 a. cadeira do $10^{\circ}$ ano do Curso de Doutorado, Direito Civil Comparado, a partir de 20 de Setembro.

Professor Miguel Reale - designado, pior ato de 21 de Novembro, do Magnífico Reitor, para reger a cadeira do $1^{\circ}$. ano do Curso de Doutorado, Teoria Geral do Estado e Partes Especiais, a partir de 20 de Setembro, em substituição ao Professor Vicente Ráo.

\section{COMEVORAÇÕES E SOLENIDADES}

10 de abril — Sessão solene da aula inaugural dos cursos da Faculdade, Sala João Mendes Junior, tendo estado a respectiva preleção a cargo do profiessor Waldemar Ferreira.

5 de maio - Solenidade da entrega da placa comemorativa do centenário de Joaquim Nabuco, que a Faculdade de Direito de Re-cife, por intermédio de seu Diretor, Professor Edgard Altino Correa de Āraujo, fez a esta Faculdade, na sala João Mendes. Falou iem nome da Congregação, agradecendo, 10 Professior José Soares de Mello.

15 de junho - Solenidade patrocinada pela Faculdade e pela Academia Paulista de Letras, comemorativa do centenário de nasicimento de Ezequiel Freire. A sessão contou com a presença 
da Congregação, tendo usado da paiavra o Professor José Soares de Mello, sobre a personalidade do homenageado, e o acadêmico Francisoo Patti, sobre Ezequiel Freire, homem de letras, poeta e escritor.

11 de agosto — Sessão solene, no Salão Nobre da Faculdade, comemorativa do $123^{\circ}$. aniversário da fundação dos cursos jurídicos no Brasil. Usaram da palavra: o Exmo. Sr. Dr. Laudo de Camargo, Ministro: Presidente do Supremo Tribunal Federal, Professor Ernesto Leme e um representante do Centro Acadêmico "XI de Agosto".

14 de novembro - Sessão de encerramento dos Cursos da Faculdade, tendo estado a mespectiva preleção a cargo do Professor Noé Azevedo, que falou sobre o tema: "Política criminal sem preocupações metafísicas".

30 de dezembro - Solenidade de colação de gráu dos bacharelandos de 1950, no Salão Nobre da Faculdade, tendo sido paraninfo - Profiessor Siqueira Ferreira.

\section{MOVIMENTO DE ALUNOS}

CONCURSO DE HABILITACGAO - FEVEREIRO DE 1950

$$
\begin{aligned}
& \text { Candidatos inscritos } \ldots \ldots \ldots, \ldots \ldots, 607 \\
& \text { sexo feminino } \ldots . \quad \ldots \quad \ldots \ldots, \ldots \quad 80 \\
& \begin{array}{lllll}
\text { sexo masculino } & \ldots & \ldots & \ldots & 527
\end{array}
\end{aligned}
$$

Candidatos que optaram pelo exame de inglês: .. $\ldots . . . . \quad 373$

$" \quad " \quad " \quad "$ francês $\ldots \ldots \ldots \ldots \ldots 231$

total: $\ldots \quad \ldots \longdiv { \ldots } \quad 6 0 4$

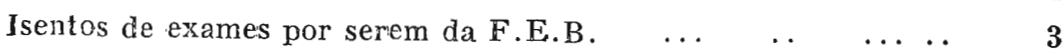

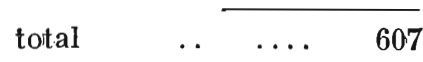

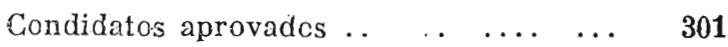

sexo masculino $\ldots \ldots \ldots \ldots . \quad \ldots \ldots \ldots .246$

sexo feminino $\ldots . \quad \ldots \quad \ldots \ldots \quad \ldots \ldots \quad 55$ 


\section{CURSO DE BACHARELADO}

Alunos matriculados:

\section{Curso Diurno}

10. an sexo masc. sexo fem.

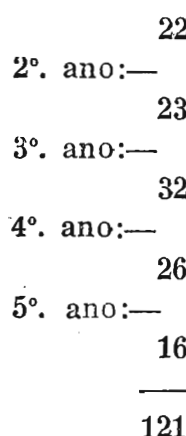

229

237

322

260

70

299

269

362

290

52

$\frac{185}{1405} \quad-\frac{21}{242}$

37

32

40

30

67

165

1213

\section{0}

192

1405
Curso Noturno

sexo masc. sexo fem. TOTAL

3

40

1

68

Total de alunos do sexo masculino: $\ldots . . \quad 1455$

feminino: .... 198

Total de alunos da Faculdade: ....... 1653 


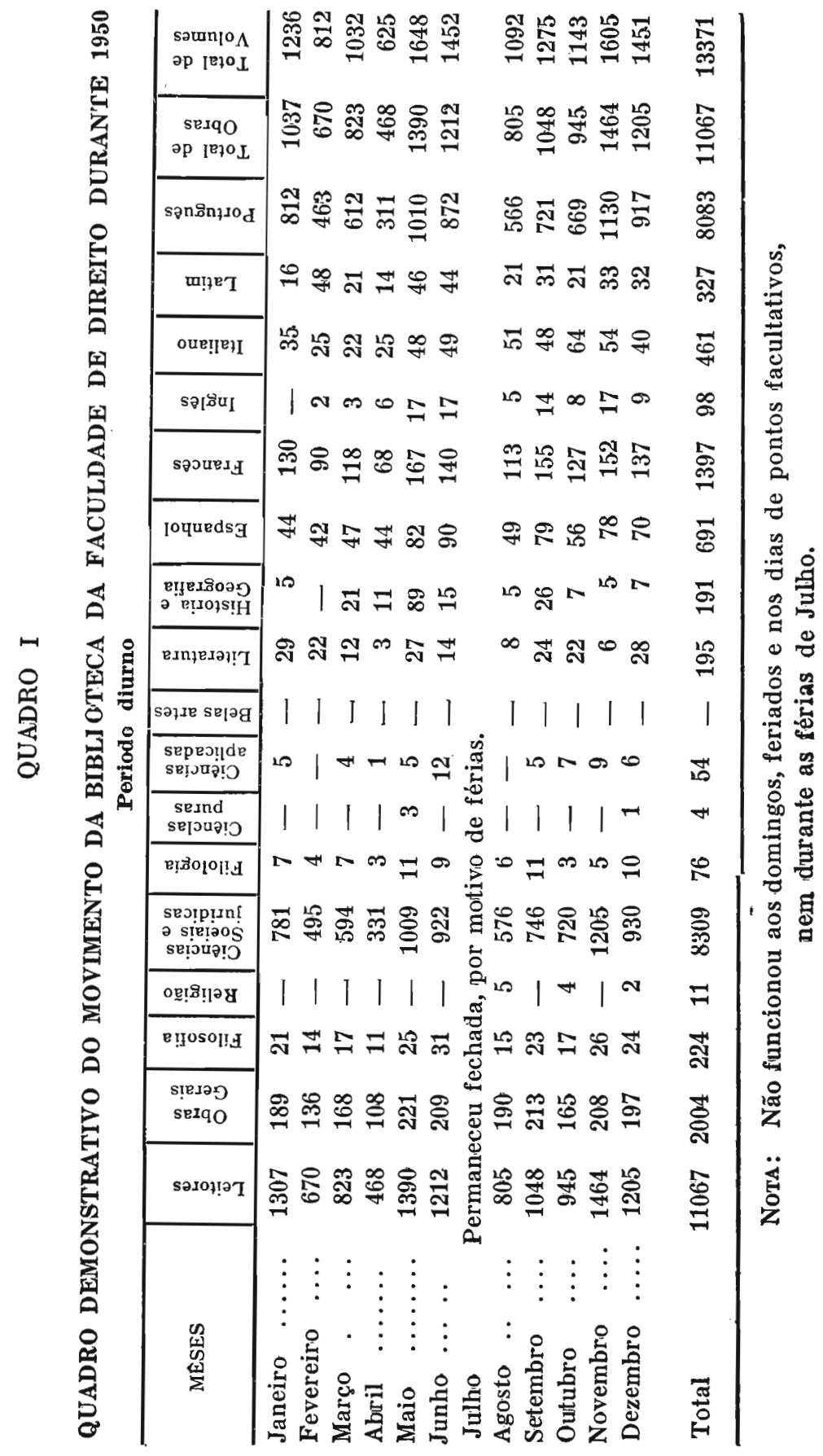




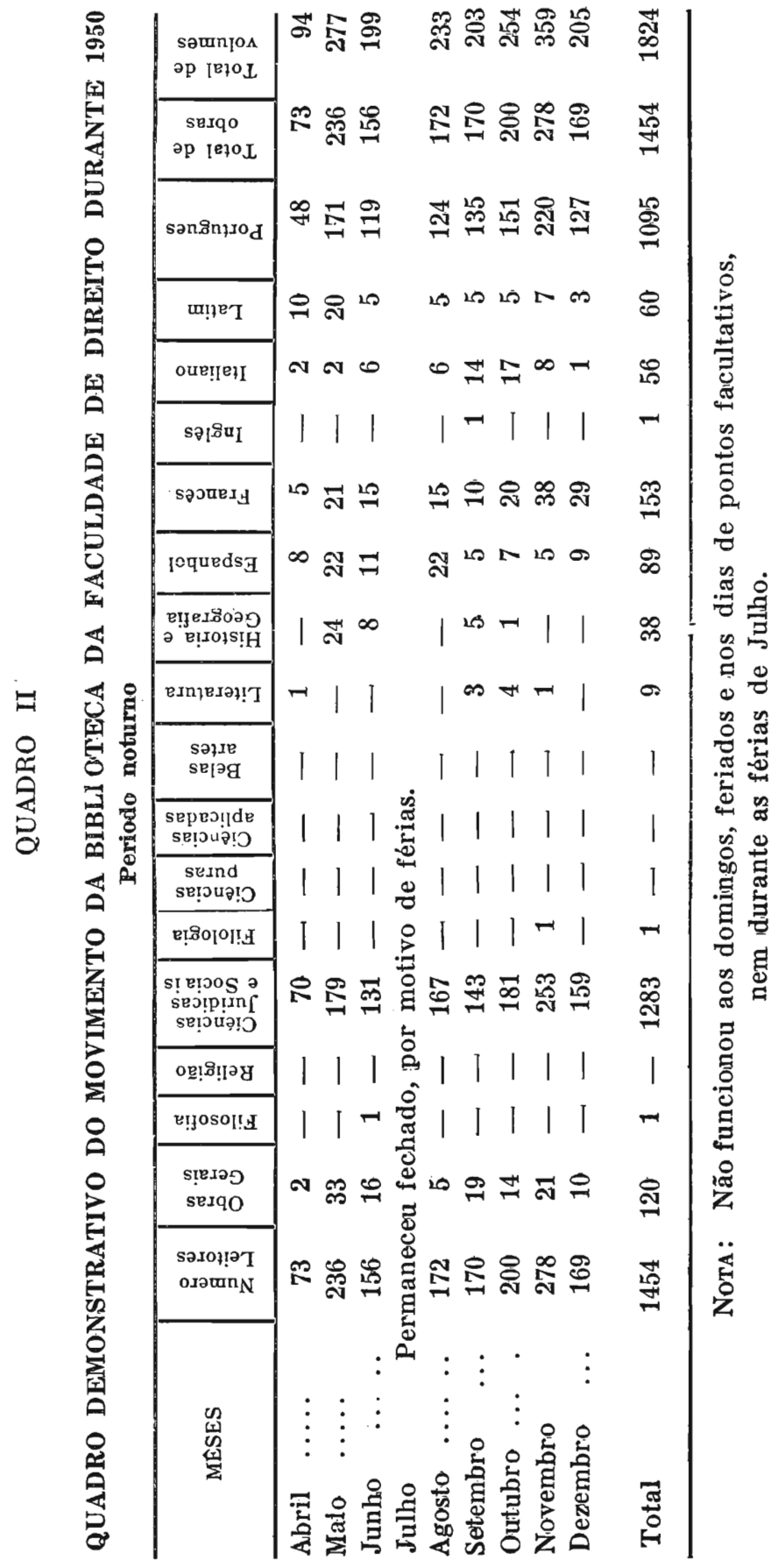

